\title{
Long-term variation in the salinity of the Southern Yellow Sea Cold Water Mass, 1976-2006
}

\author{
Ang $\mathrm{Li}^{1,2,3} \cdot$ Fei $\mathrm{Yu}^{2} \cdot$ Guangcheng $\mathrm{Si}^{2} \cdot$ Chuanjie $\mathrm{Wei}^{2}$
}

Received: 12 February 2016 / Revised: 20 November 2016 / Accepted: 22 November 2016 / Published online: 23 January 2017

(C) The Author(s) 2017. This article is published with open access at Springerlink.com

\begin{abstract}
This paper discusses the long-term variation in the salinity of the Southern Yellow Sea Cold Water Mass (SYSCWM) and examines factors influencing the SYSCWM based on hydrographic datasets of the China National Standard section and the Korea Oceanographic Data Center. The mean salinity at the center of the SYSCWM showed a decreasing long-term trend. In empirical orthogonal function (EOF) analysis, the second EOF mode showed a similar long-term trend. The mean salinity of the center of the SYSCWM was related to the intrusion of saline water from the Yellow Sea Warm Current (YSWC), the salinity of the source area of the YSWC, the evaporation minus precipitation (E-P) flux, and discharge from the Changjiang River. The decreasing salinity trend to the southwest of Cheju Island produced a freshening trend in the YSWC, resulting in a reduction in the salinity of the SYSCWM. The freshening trends of the water from the northwest Pacific and the South China Sea were seen as the reason for the decreasing salinity trend from the intrusion of water into the Yellow Sea (YS). The freshwater flux influenced the surface salinity and was brought to deep layers by strong mixing in winter. The mean E-P flux signal and Changjiang River discharge signal lagged the first
\end{abstract}

Fei Yu

yuf@qdio.ac.cn

1 Key Laboratory of Research on Marine Hazards Forecasting, National Marine Environmental Forecasting Center, State Oceanic Administration, Beijing 100081, China

2 Research and Development Center of Marine Environmental Engineering and Technology, Institute of Oceanography, Chinese Academy of Sciences, 7 Nanhai Road, Qingdao 266071, Shandong, China

3 University of Chinese Academy of Sciences, Beijing 100049, China principal component of the SYSCWM by approximately 5 months.

Keywords Southern Yellow Sea Cold Water Mass . Long-term trend · Interannual salinity variability · Yellow Sea Warm Current · Influence factor

\section{Introduction}

The Yellow Sea (YS) is a semi-closed marginal water body between the Korean Peninsula and the Chinese mainland. It is located at $31^{\circ} 40^{\prime}-39^{\circ} 50^{\prime} \mathrm{N}$ and $119^{\circ} 10^{\prime}-126^{\circ} 50^{\prime} \mathrm{E}$ and is open to the East China Sea to the south. The Yellow Sea Cold Water Mass (YSCWM), a significant seasonal water mass characterized by high salinity, occupies approximately one-third of the deep layer of the YS in the summer (Su and Weng 1994). The YSCWM has more conservative temperature-salinity characteristics than the other water masses in the YS. It also has a substantial impact on the biomass and acquisition of fishery resources in the YS (Du et al. 1996; Wang et al. 2003; Zhang et al. 2007). A line from Changsangot in the Korean Peninsula to Chengshantou in the Shandong Peninsula divides the YS into the northern and southern YS. The YSCWM typically has three cold cores. The cold core in the northern YS is called the Northern Yellow Sea Cold Water Mass (NYSCWM), and the two cold cores in the southern YS are called the Southern Yellow Sea Cold Water Mass (SYSCWM).

The YSCWM has obvious seasonal variability. It forms in the spring, matures in the summer, recedes in the autumn, and completely disappears in the winter. The existence of the YSCWM was discovered by Uda (1934). $\mathrm{He}$ et al. (1959) first studied its formation mechanism, and concluded that it was formed locally in the previous 
winter. Since then, many studies of the YSCWM formation mechanism have been published. The formation of the seasonal thermocline (Ren and Zhan 2005; Yu et al. 2006), the surface heat flux in winter (Guan 1963), the strong vertical mixing in winter (Hur et al. 1999), and tidal horizontal mixing (Lee and Beardsley 1999; Zhao 1986) are all seen as important mechanisms involved in the formation of the YSCWM.

With the accumulation of historical observational data, many academic sectors began to take a greater interest in the long-term variability in the YSCWM. Early studies explored the distribution range, low-salinity center, volume, and thermohaline characteristics of the YSCWM using similar coefficient methods (Weng et al. 1988; Zhang and Yang 1996). More recent studies have reported on interannual variations in the position, depth, and intensity of the thermocline dome of the SYSCWM using empirical orthogonal function analysis (Bai et al. 2004; Hu and Wang 2004). Changes in the SYSCWM temperature are closely related to changes in atmospheric forcing during summer and winter, such as the Siberian High, the Aleutian Low, and sea surface temperature (SST) in the Kuroshio and the Alaska currents (Park et al. 2011). An increase in the southern limit of the SYSCWM in summer was reported to occur after a decrease in the SST of the YS the previous winter (Yang et al. 2014). Researchers found that the trend toward increasing SST in the YS was consistent with the climate warming in northern China and the adjacent seas (Lin et al. 2005), and was related to the bathymetry and Arctic Oscillation signals (Park et al. 2015).

Compared with the number of studies on interannual temperature variability in the SYSCWM, there is relatively little research on interannual salinity variability. Lv et al. (2009) found that the winter salinity of the northern YS at depths of 0,10 , and $20 \mathrm{~m}$ has shown an increase since the 1950s. Similarly, Ma et al. (2006) reported that the mean salinity of the Dalian-Chengshantou section was increasing. Jiang et al. (2007) analyzed the bottom salinity of a station at the center of the Dalian-Chengshantou section and found no clear salinity changes in the NYSCWM. The mean salinity of the NYSCWM center demonstrated a slightly decreasing trend that was related to the Yellow Sea Warm Current (YSWC) and the E-P flux of the northern Yellow Sea (Li et al. 2015). Wei et al. (2010) reported that the summer temperature-salinity properties of the YSCWM corresponded to the YSWC in winter. The surface salinity in the East China Sea exhibited a long-term decreasing trend (Eko et al. 2008), and the El Niño-Southern Oscillation (ENSO) affected interannual variability in surface salinity by modifying precipitation and Changjiang river discharge (CRD). However, the long-term variation in SYSCWM salinity is still unclear, and further work is needed.
The present study aims to identify characteristics of the long-term trends in SYSCWM salinity and to explore their causes. In Sect. 2, the information in various datasets used in this study is described. In Sect. 3, we present linear trend analysis and empirical orthogonal function (EOF) analysis of SYSCWM salinity. In Sect. 4, we examine the relationship between the principal component of the salinity and various factors, including the intrusion of the YSWC, the E-P flux, CRD, and the salinity of the source. Finally, in Sect. 5, we summarize the interannual trend properties of the salinity of the SYSCWM and the main factors underlying the trend.

\section{Data}

\subsection{China standard section survey data}

These observational data were obtained and archived by the State Oceanic Administration of China. The dataset represents the longest record among the various in situ observational data in the western YS. Salinity data for the $36^{\circ} \mathrm{N}$ standard section from 1976 to 2006 were used to analyze interannual variability in the western half of the SYSCWM. A total of 11 stations are included along the $36^{\circ} \mathrm{N}$ section, as shown in Fig. 1. The distances of the two neighboring stations of the $36^{\circ} \mathrm{N}$ section are $0.5^{\circ}$ at the central YS and $0.25^{\circ}$ near the coast. The eastern edge of this section reaches as far as $124.5^{\circ} \mathrm{E}$. The section covers the main part of the SYSCWM, so these data can be used to demonstrate the SYSCWM salinity characteristics. Standard depths for the data are $0,5,10,15,20,25,30,35,50$, and $75 \mathrm{~m}$, plus the bottom depth. Winter and summer observations were made in February and August, respectively. August data are missing in 1993, and February data in 1976, 1984, and 1996.

\subsection{Korea Oceanographic Data Center (KODC) data}

The KODC dataset includes bi-monthly observation data. This dataset, which has been routinely collected by the National Fisheries Research and Development Institute of Korea since 1960, contains various oceanographic parameters, including salinity, oxygen, and nutrients. The data for the 313 section from 1976 to 2006 are used in this study, and a total of nine stations are included. The $313 \mathrm{sec}-$ tion $\left(33.41^{\circ} \mathrm{N}\right.$ section) at the southwest of Cheju Island stretches across the source area of the YSWC, as shown in Fig. 1. Zonal spacing of the KODC data is approximately $0.21^{\circ}$, and the longitude of this section ranges from $124.4^{\circ} \mathrm{E}$ to $126^{\circ} \mathrm{E}$. The vertical levels of KODC data are $0,10,20,30,50$, and $75 \mathrm{~m}$, plus the bottom depth. The summer (winter) observations were conducted in August 


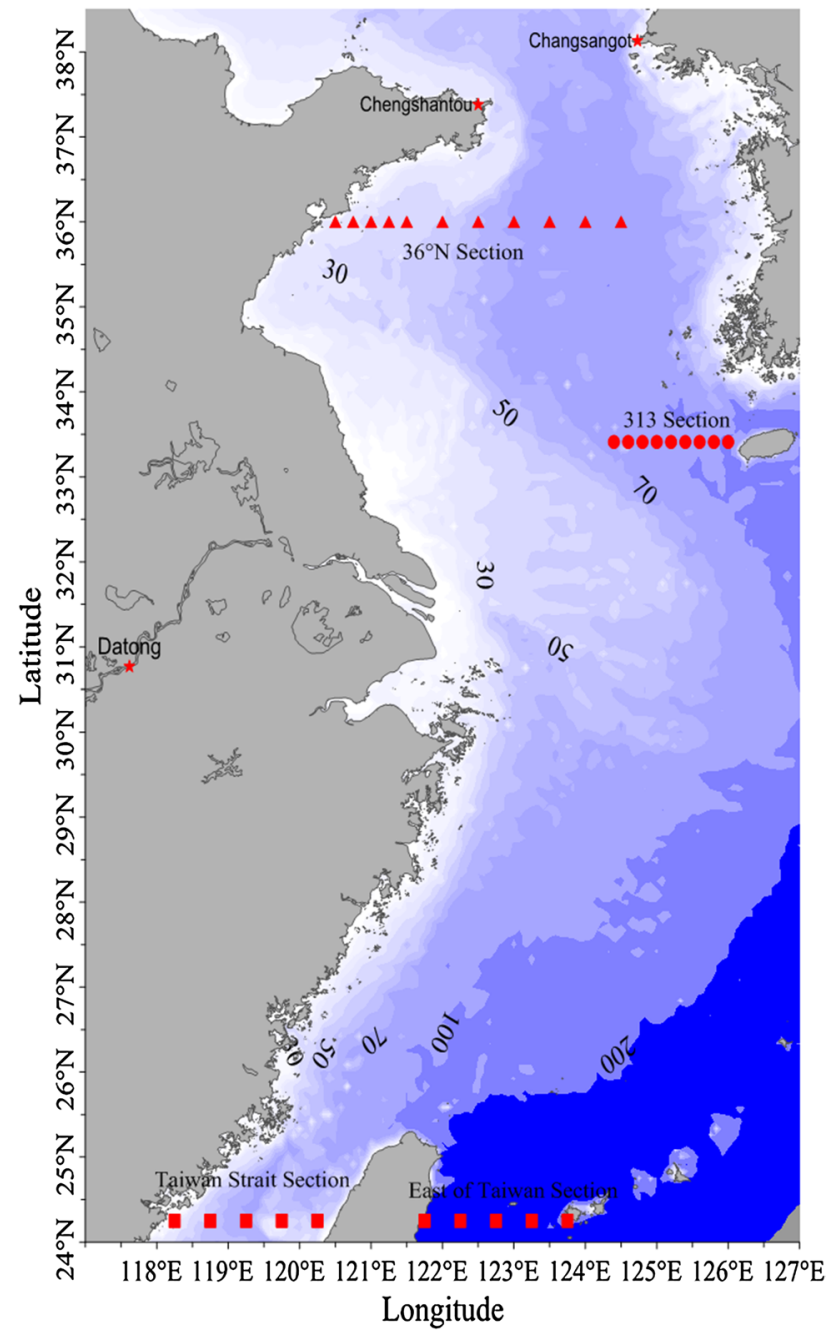

Fig. 1 Locations of survey stations: $36^{\circ} \mathrm{N}$ section (triangles), KODC 313 section (circles), SODA Taiwan Strait section (squares), East of Taiwan section (squares), Datong station, Chengshantou, and Changsangot (star), and bathymetry (shading)

(February). The observed period for this dataset has good consistency.

\subsection{ECMWF re-analysis (ERA)-Interim reanalysis data}

The variability in the salinity of the SYSCWM may be associated with the surrounding freshwater flux conditions. We used E-P flux data over the entire YS region as the background field data. The monthly mean E-P flux data were used to analyze the freshwater flux. The 28 years of data began in 1979. These data were downloaded from the ERA-Interim reanalysis dataset of the European Centre for Medium-Range Weather Forecasts (ECMWF). Dee et al. (2011) described this dataset in detail. The horizontal resolution of the data is $0.125^{\circ}$.

\subsection{Changjiang River discharge data}

Runoff from the Changjiang River is a major contributor of freshwater input to the East China Sea. The monthly mean discharge data for the Datong station $\left(30^{\circ} 46^{\prime} \mathrm{N}, 117^{\circ} 37^{\prime} \mathrm{E}\right)$, which is located at the downstream area, were used to analyze the runoff input from the Changjiang River. These data span the period from 1975 to 2006.

\subsection{Simple Ocean Data Assimilation (SODA) reanalysis data}

In this study, we also used SODA 2.2.4 reanalysis data. The horizontal resolution of the data is $0.5^{\circ} \times 0.5^{\circ}$. There are 40 levels in a vertical direction. The salinity data above $700 \mathrm{~m}$ from 1975 to 2006 are used to calculate the salinity transport of the Kuroshio and the South China Sea. The SODA assimilation system ingests a wide variety of observations, including hydrographic profiles, ocean station data, moored temperature and salinity measurements, surface temperature, and salinity observations from a variety of instruments (e.g., mechanical bathythermograph [MBT], expendable bathythermograph [XBT], CTD), SST from nighttime infrared observations from satellites, and satellite-based sea-level altimetry.

\section{Interannual variation in salinity of the SYSCWM}

\subsection{Interannual salinity trend}

The boundary of the $36^{\circ} \mathrm{N}$ section is near $124.5^{\circ} \mathrm{E}$, which is at the YS trough; thus the data for this section can represent the salinity characteristics of the main part of the SYSCWM. As the center of high salinity can portray the characteristics of the SYSCWM center (Fig. 2), we selected the weighted mean salinity in the area of the $36^{\circ} \mathrm{N}$ section below $30 \mathrm{~m}$ and east of $123^{\circ} \mathrm{E}$ to represent the mean salinity of the SYSCWM in summer. The weighted mean salinity is calculated using the formula: $\bar{S}=\frac{\sum_{j=1}^{m} \sum_{i=1}^{n_{j}-1}\left(S_{i, j}+S_{i+1, j}\right) / 2 \times\left(Z_{i+1, j}-Z_{i, j}\right)}{\sum_{j=1}^{m}\left(Z_{n_{j}, j}-Z_{1, j}\right)}$, where $m$ is the number of stations east of $123^{\circ} \mathrm{E}$ along the $36^{\circ} \mathrm{N}$ section, $n$ is the number of data points below $30 \mathrm{~m}$ at station $j, Z$ is depth, and $S$ is salinity. The weighted mean salinity of this section is shown in Fig. 3a. The halocline was above $30 \mathrm{~m}$. This index shows the vertically averaged salinity of the SYSCWM area. The variation in mean salinity of the SYSCWM is shown in Fig. 3a. The linear trend analysis shows a decreasing trend of 0.01 per year in the mean salinity of the SYSCWM. The maximum salinity in 


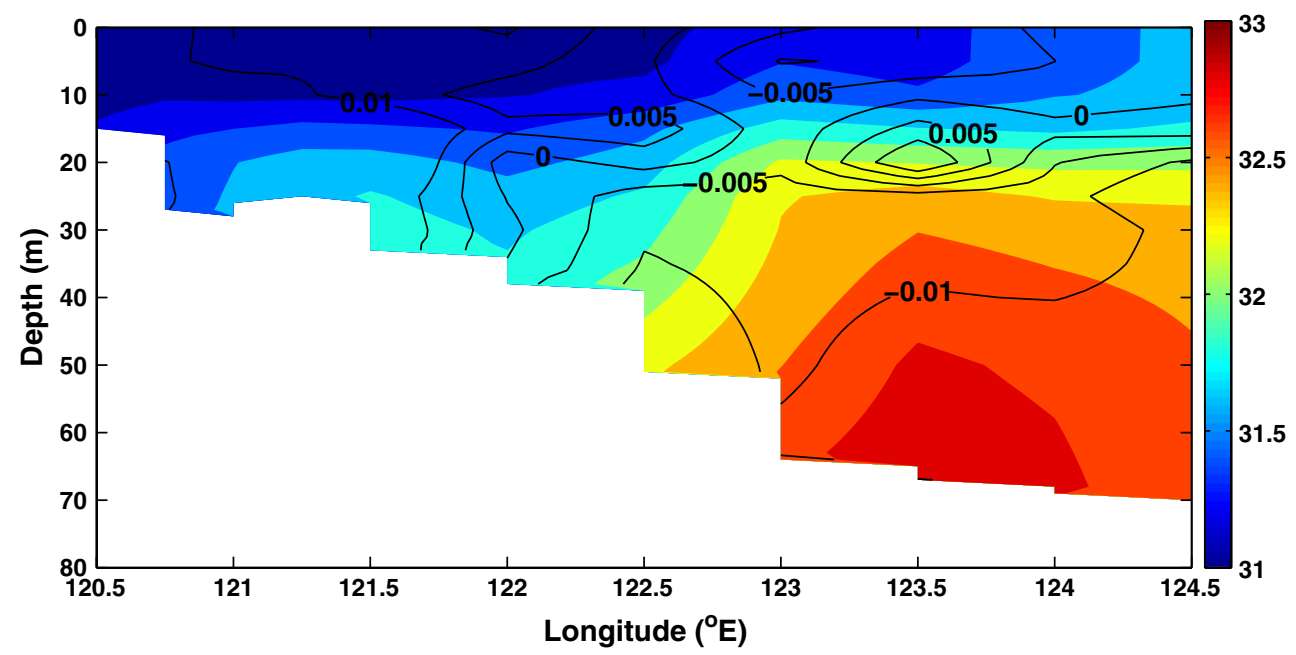

Fig. 2 Mean salinity (shading) and linear salinity trend (year ${ }^{-1}$, contours) using the data from the $36^{\circ} \mathrm{N}$ section in August, 1976-2006

Fig. 3 Weighted mean salinity (a) and maximum salinity (b) of the SYSCWM in August (solid line) and their linear trends (year ${ }^{-1}$, dashed lines)
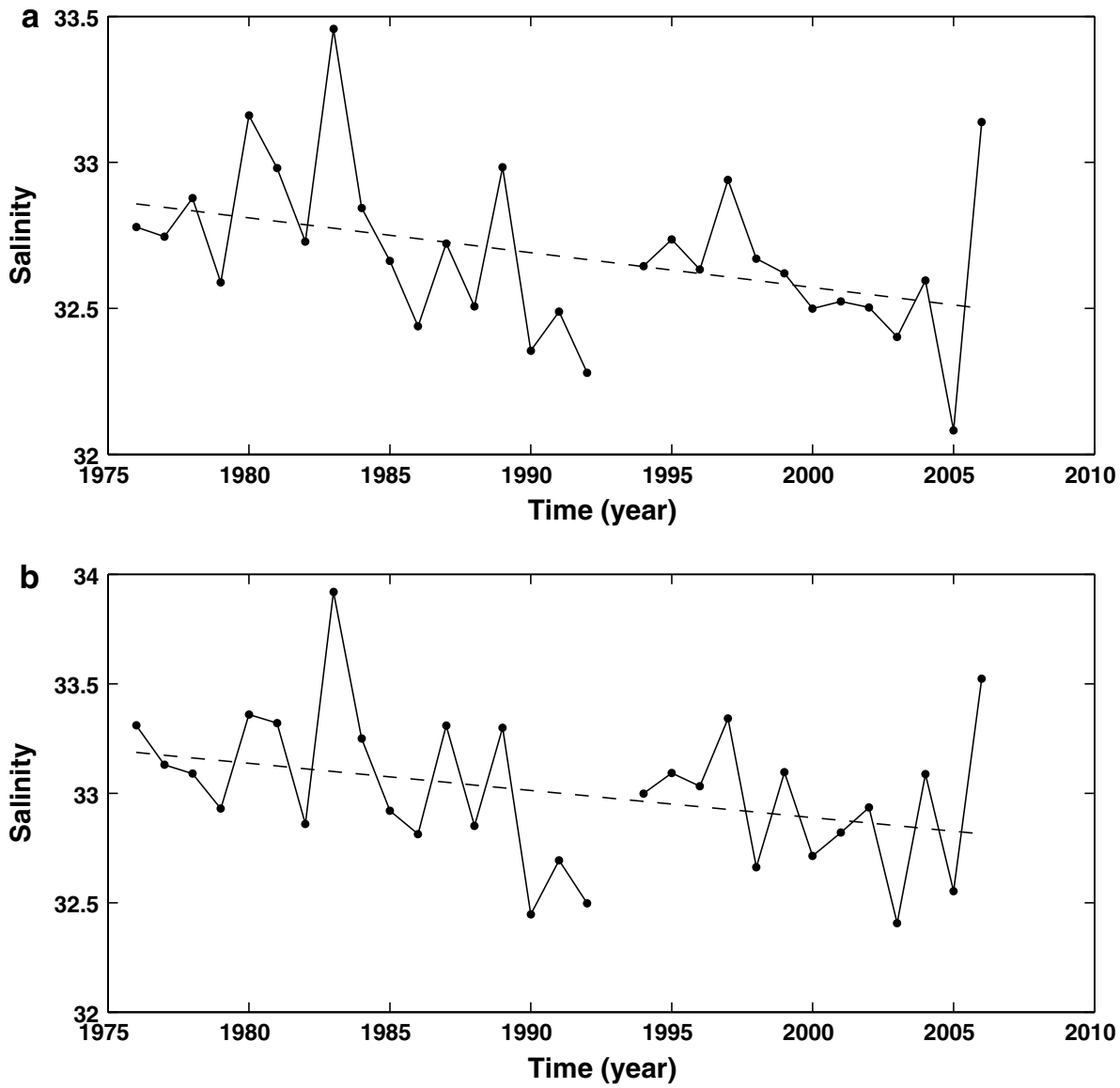

the $36^{\circ} \mathrm{N}$ section in summer also exhibited a falling trend (Fig. 3b). The maximum salinity trend was -0.01 per year, which is similar to that of the SYSCWM mean salinity. The weighted mean salinity and maximum salinity indices indicate a decreasing trend in SYSCWM salinity.
To further investigate the SYSCWM long-term salinity trend, a linear time series trend of the $36^{\circ} \mathrm{N}$ section data was calculated (Fig. 2; solid contours). The salinity trend of the coastal area is positive and may be related to the coastal current from the northern YS. The salinity of the water 

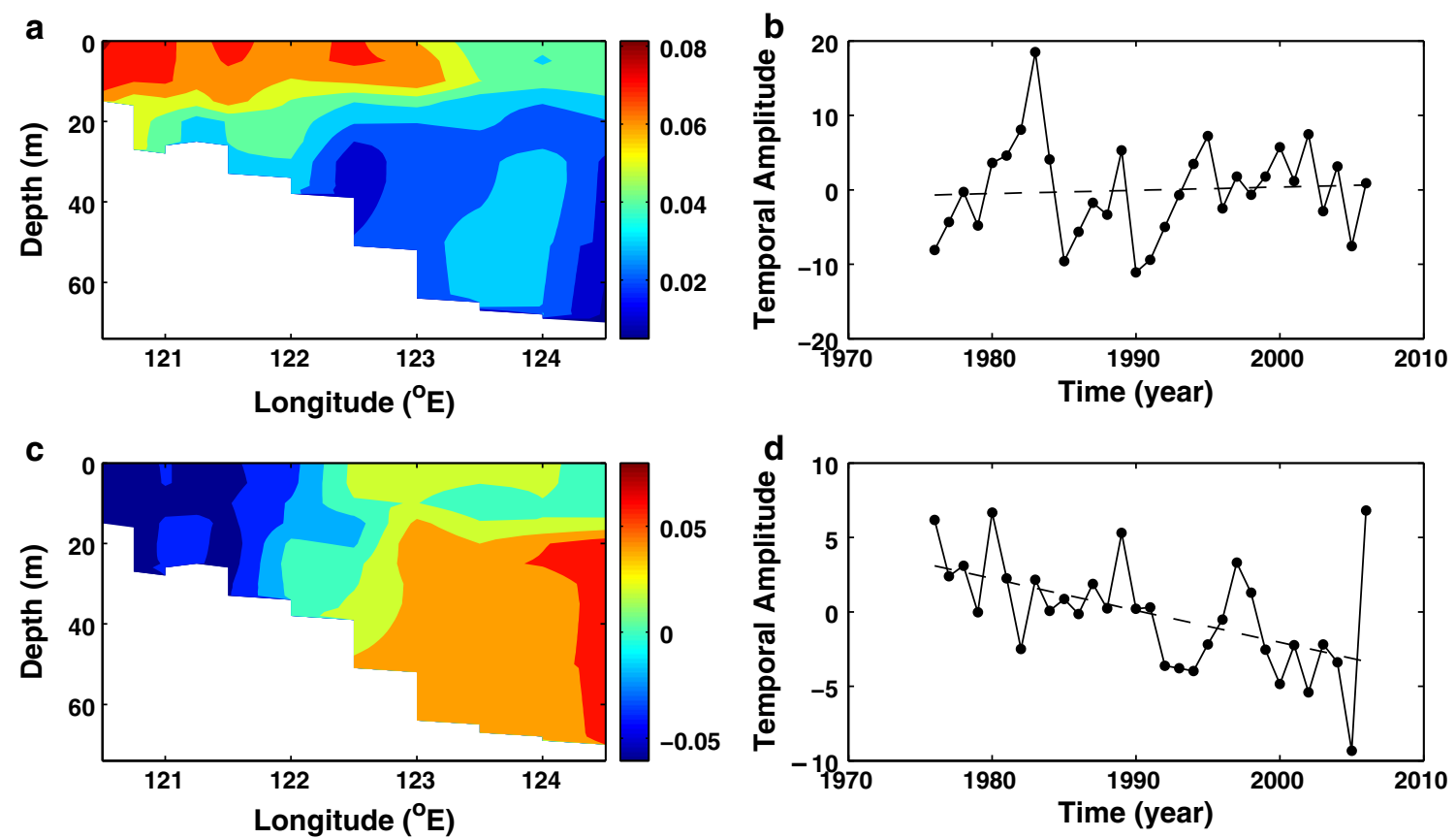

Fig. 4 The spatial distribution of the first two EOF modes $(\mathbf{a}, \mathbf{c})$; the time coefficients $(\mathbf{b}, \mathbf{d})$ (solid line with solid dots) and the linear trends (year ${ }^{-1}$, dashed line) of the salinity of the $36^{\circ} \mathrm{N}$ section in summer

from the northern YS exhibited an increasing trend (Lin et al. 2001; Ma et al. 2006; Lv et al. 2009). Wu et al. (2004) concluded that the sustained and rapid reduction in Yellow River runoff was a major reason for the increased salinity in the Bohai Sea. The interannual salinity trends at the eastern part of the section (east of $122.5^{\circ} \mathrm{E}$ ) were different from those of the coastal area. The maximum descending trend reached 0.01 per year at deep layers in this section. These interannual variation characteristics were consistent with the mean salinity trend of the SYSCWM, which was described earlier. The analysis of the section data indicates long-term decreasing trends at the area of the SYSCWM.

\subsection{Empirical orthogonal function analysis}

Based on 31 years of salinity data along the $36^{\circ} \mathrm{N}$ section, the first two modes of the EOF analysis are shown in Fig. 4. The missing data in 1993 are interpolated using mean values of the 1992 and 1994 data. The first two EOF modes account for 50 and $17 \%$ of the total variance, respectively. The first mode indicates interannual salinity changes along the $36^{\circ} \mathrm{N}$ section. The high values are mainly at the upper layers of the section. The positions of low-value centers of the first mode are consistent with two cold center areas of the SYSCWM. A time series of the first principal component showed interannual salinity variation in the entire section and a slight increase in surface salinity, which is consistent with the linear trend for the coastal area of the $36^{\circ} \mathrm{N}$ section (Fig. 2). The second mode shows a similar distribution, with a linear salinity trend for the $36^{\circ} \mathrm{N}$ section (Fig. 3). This mode can be seen as the salinity trend of the SYSCWM mode. The values of the second mode in the coastal area are negative, whereas those in the central area of the SYSCWM are positive. The second principal component shows a decreasing trend. The distributions of the first two EOF modes and the principal components generally reveal a decreasing trend in SYSCWM salinity and an increasing trend in the coastal water. The difference in salinity between the SYSCWM and the coastal water may decrease according to those trends.

In this section, we examined different salinity indices for the SYSCWM, including the mean value of the high-salinity center, maximum salinity, and the first two principal components of the salinity of the $36^{\circ} \mathrm{N}$ section. A decreasing salinity trend in the SYSCWM was confirmed. Factors influencing this trend are explored in subsequent sections.

\section{Factors influencing the salinity of the SYSCWM}

\subsection{Variation in winter salinity}

The local water mass in winter is a major source of the YSCWM (He et al. 1959). Therefore, the salinity of the YS in winter is an important factor affecting the variability of the SYSCWM salinity in summer. We calculated the linear 
Fig. 5 Mean salinity (shading) and linear salinity trend (year ${ }^{-1}$, contours) using the data from the $36^{\circ} \mathrm{N}$ section in February, 1976-2006

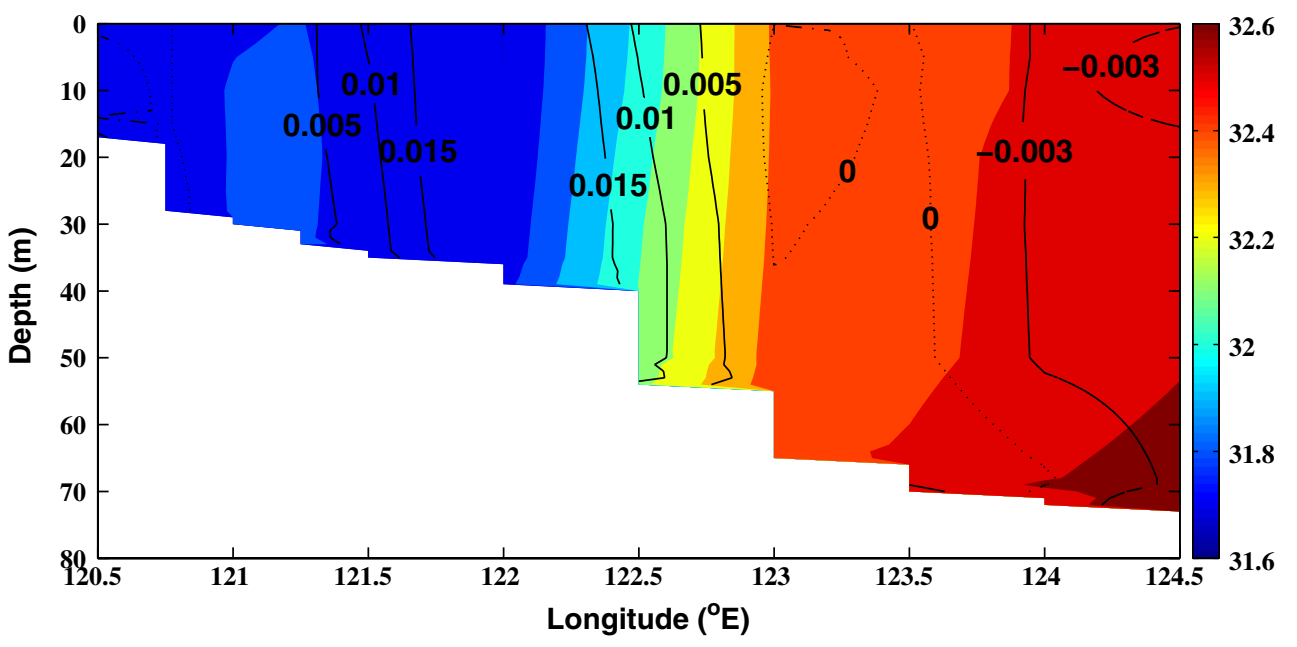

Fig. 6 The time coefficients of the second EOF mode of salinity in August (red dashed curve) and that in February (blue dashed curve) from the $36^{\circ} \mathrm{N}$ section

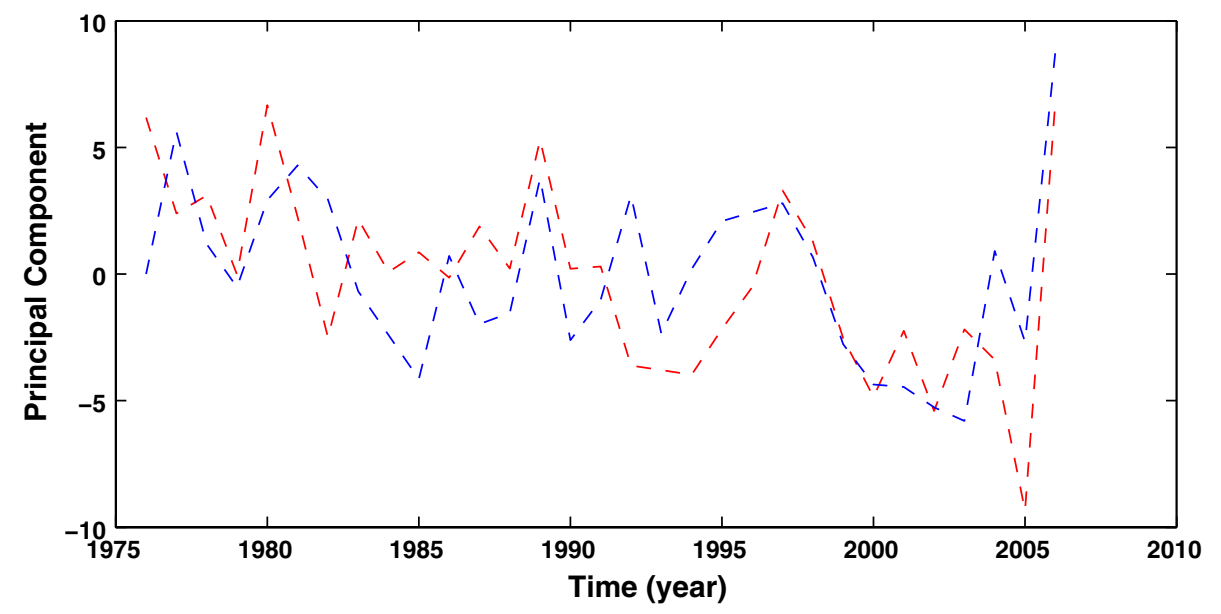

trends and mean salinity using the $36^{\circ} \mathrm{N}$ salinity data for February to represent winter salinity conditions (Fig. 5). Owing to the influence of strong mixing caused by the winter monsoon, the winter salinity of the YS is nearly vertically constant in the upper and lower layers. Data for salinity east of $123.5^{\circ} \mathrm{E}$ show decreasing trends. This area is similar to the area of the YSWC axis. We selected weighted mean salinity below $30 \mathrm{~m}$ in the $36^{\circ} \mathrm{N}$ section in winter to investigate the mean salinity in the YS. Data for this area are the same in winter as in summer. The YSWC is a major source of saline water input into the YS. Although the intrusion of the YSWC showed a clear westward shift along the western slope of the YS trough, the high-salinity input of the YSWC affected the salinity of the entire YS. These mean values of deep-layer salinity along the $36^{\circ} \mathrm{N}$ section revealed the intrusion of the YSWC into the SYSCWM to some degree. The high-salinity water input of the YSWC is seen as a significant factor influencing SYSCWM salinity. The decreasing salinity trend in the central area of the YS in winter indicates that the source of the SYSCWM exhibited a freshening trend. The temporal variation in the second EOF mode of salinity in summer is related to that in winter (Fig. 6). The correlation coefficient of these two indices is 0.58 .

We applied EOF analysis of the salinity of the $36^{\circ} \mathrm{N}$ section in February to identify the spatiotemporal variability of the SYSCWM in winter. The second EOF accounts for $22 \%$ of the total variance. The second EOF mode (Fig. $7 \mathrm{~b}$ ) represents long-term winter salinity trends, and shows a distribution similar to the linear salinity trend for the $36^{\circ} \mathrm{N}$ section in winter (Fig. 5). Since the value of the second mode to the east of $123^{\circ} \mathrm{E}$ is positive, the second principal component shows a decreasing trend. The second EOF mode distribution and the second principal component generally illustrate that the salinity of the YSWC exhibits a decreasing trend. The second principal component of the salinity in winter is related to that in summer. The correlation coefficient of these two indices is 0.58 . The second principal component also indicates a decreasing trend in the saline water brought in by the YSWC. 
Fig. 7 The spatial distribution of the second EOF modes (a); the time coefficients (b) (solid line with solid dots) and the linear trends ( year $^{-1}$, dashed line) of the $36^{\circ} \mathrm{N}$ section in winter
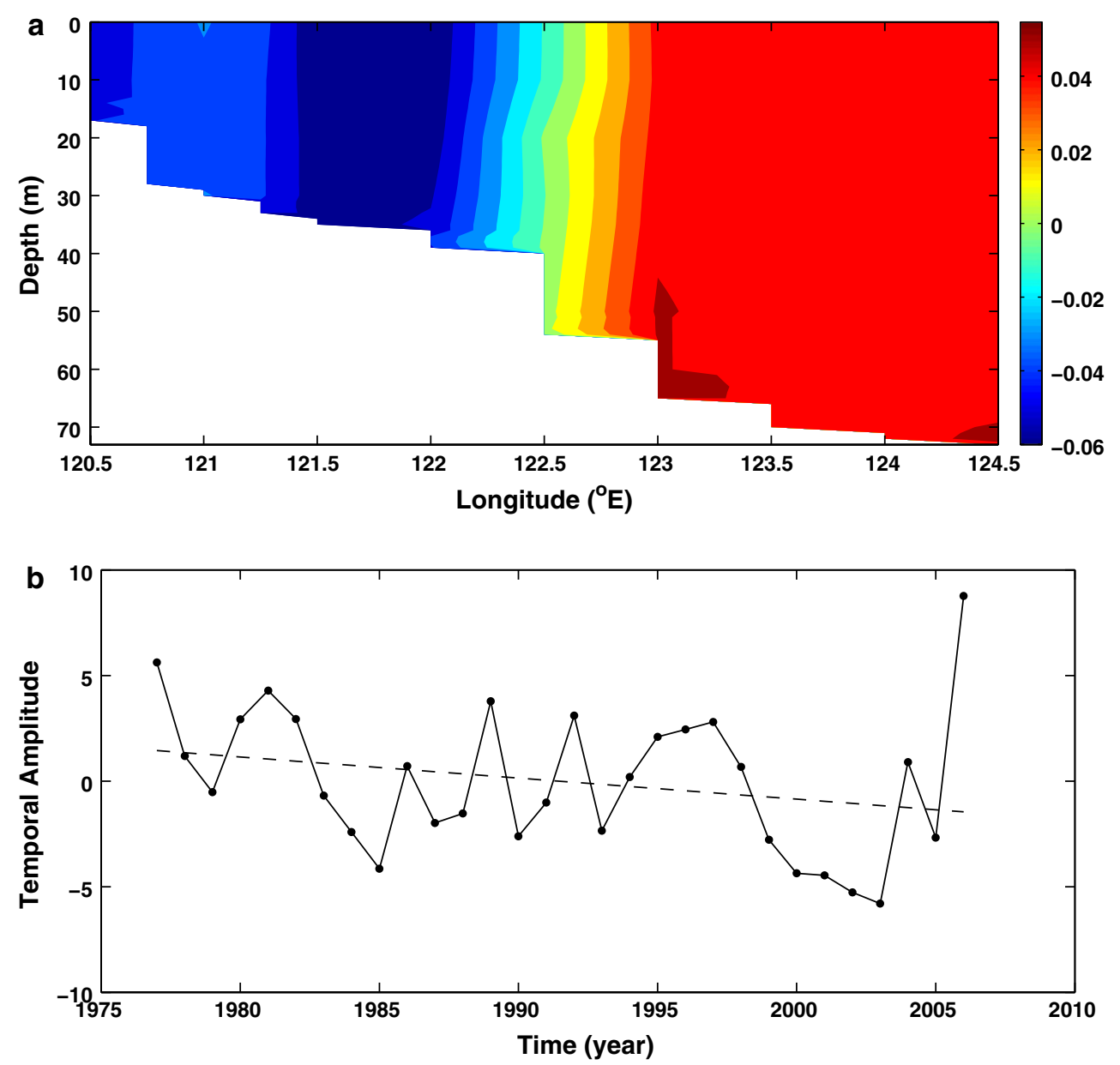

The correlation analysis of the EOF results and the weighted mean salinity of the SYSCWM area indicate that the saline water brought by the YSWC showed a decreasing trend. The lower salinity of the YSWC water led to lower SYSCWM salinity in summer.

\subsection{Salinity variation in the YSWC source area}

The 313 section is located to the west of Cheju Island, and its position can be seen at the source area of the YSWC. Therefore, the salinity of this section can be seen
Fig. 8 The second EOF principal component of the $36^{\circ} \mathrm{N}$ section in summer (red dashed curve) and the mean salinity of the western part of the $313 \mathrm{sec}-$ tion in December (blue dashed curve)

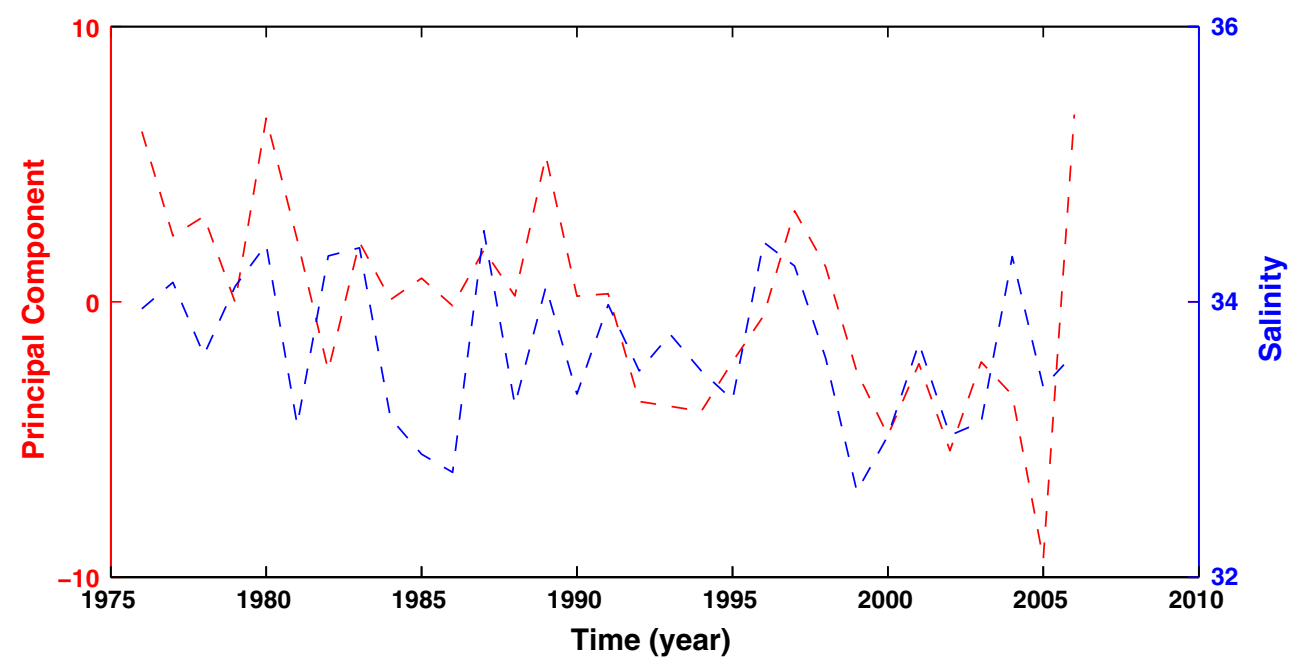




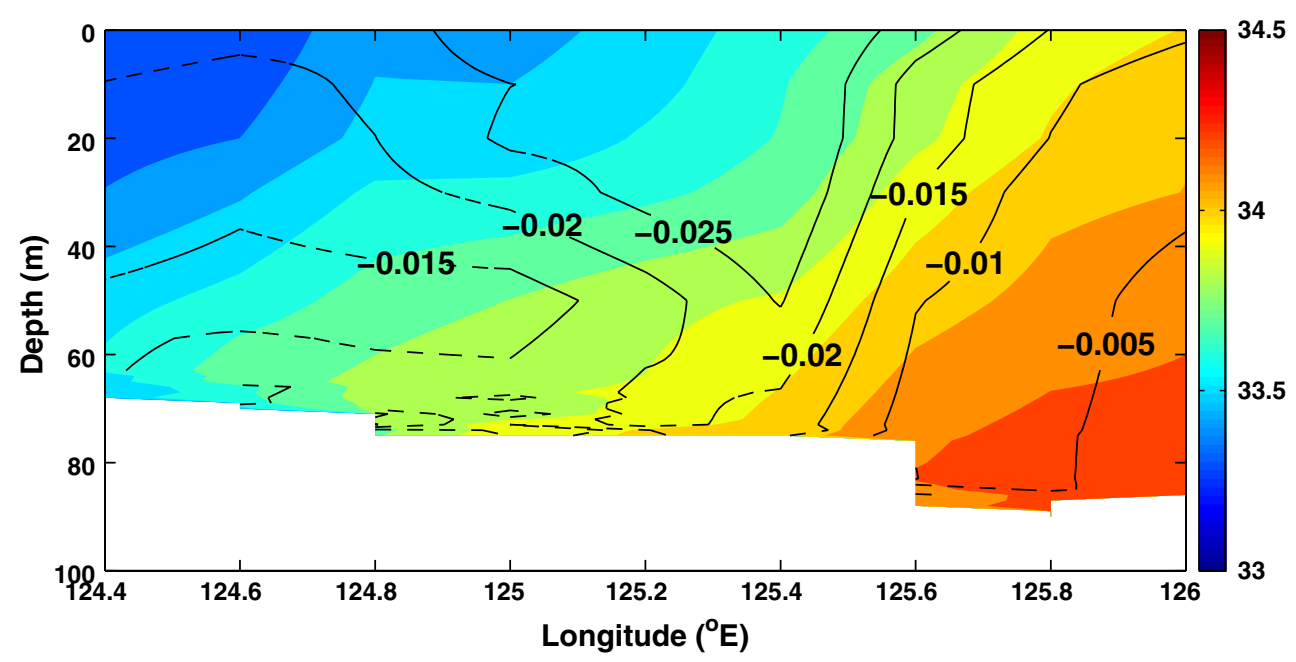

Fig. 9 Mean salinity (shading) and linear salinity trend (year ${ }^{-1}$, contours) using the data from the 313 section in December, 1976-2006

as somewhat characteristic of the salinity of the YSWC source. In the study by Lie et al. (2000), the drifters that moved into the Cheju Strait were all to the east of $125^{\circ} \mathrm{E}$. The water in this area flows primarily into the Cheju Strait with the Cheju Warm Current. Therefore, we calculate the weighted mean salinity of the area under $30 \mathrm{~m}$, which is to the west of $125^{\circ} \mathrm{E}$. The computation used here is the same as that used for the $36^{\circ} \mathrm{N}$ section. The $313 \mathrm{sec}-$ tion is approximately $310 \mathrm{~km}$ from the SYSCWM area along the $36^{\circ} \mathrm{N}$ section. As the speed of the YSWC was
Fig. 10 Weighted mean salinity (solid line) of the Taiwan Strait (a) and the east of Taiwan (b), and their linear trends $\left(\right.$ year $^{-1}$ dashed lines)
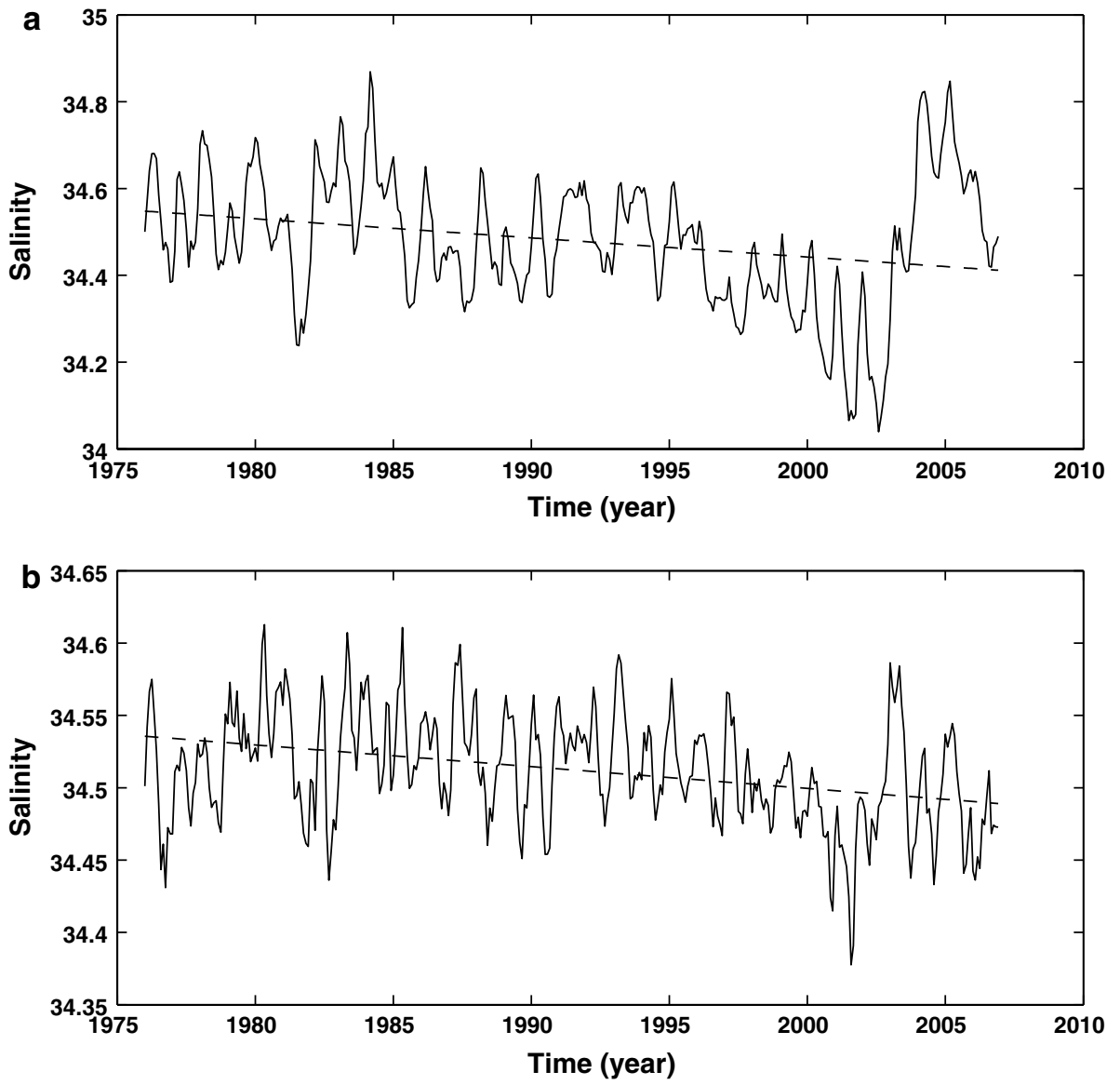
approximately $6 \mathrm{~cm} / \mathrm{s}$ (Wang et al. 2009), the YSWC would reach $36^{\circ} \mathrm{N}$ from the source area in approximately 2 months. The mean salinity of the source area in December has coherence with the second principal component of the $36^{\circ} \mathrm{N}$ section in summer (Fig. 8). The correlation coefficient is 0.37 , at a $90 \%$ significance level. The salinity of the entire section also demonstrated a decreasing trend (Fig. 9). The freshening trend of the YSWC source area reached 0.015-0.02 per year. The decreasing salinity trend of the source area water explains the decreasing salinity trend of the SYSCWM. The freshening trend of the YSWC reduced the horizontal salinity input to the YS, which led to the lower salinity of the SYSCWM.

The Kuroshio and the South China Sea are two sources of high-salinity water for the YS. We calculated the weighted mean salinity of the Taiwan Strait (TS) section from $118^{\circ} \mathrm{E}$ to $120.5^{\circ} \mathrm{E}$ and the east of Taiwan (ET) section from $121.75^{\circ} \mathrm{E}$ to $124^{\circ} \mathrm{E}$ at $24.25^{\circ} \mathrm{N}$ using the SODA reanalysis data. The calculation method is the same as that used to calculate the mean salinity of the SYSCWM. These two sections both showed decreasing salinity trends (Fig. 10). The decreasing salinity trends of the Kuroshio and South China Sea water caused lower-salinity water to be brought to the East China Sea, which then reduced the salinity of the source area of the YSWC, thus further explaining the long-term salinity variation in the SYSCWM. The salinity trend of the Kuroshio water was consistent with the results of Nan et al. (2015), where a freshening trend in surface salinity of -0.0042 per year was found, with the change in the air-sea freshwater flux as the leading factor.

\subsection{Variation in freshwater input}

Freshwater input, such as E-P flux and river discharge, is an important factor affecting the salinity of the YS. In this paper, the area-averaged monthly E-P flux of the YS (119$127^{\circ} \mathrm{E}, 33-41^{\circ} \mathrm{N}$ ) is calculated to describe the evaporation
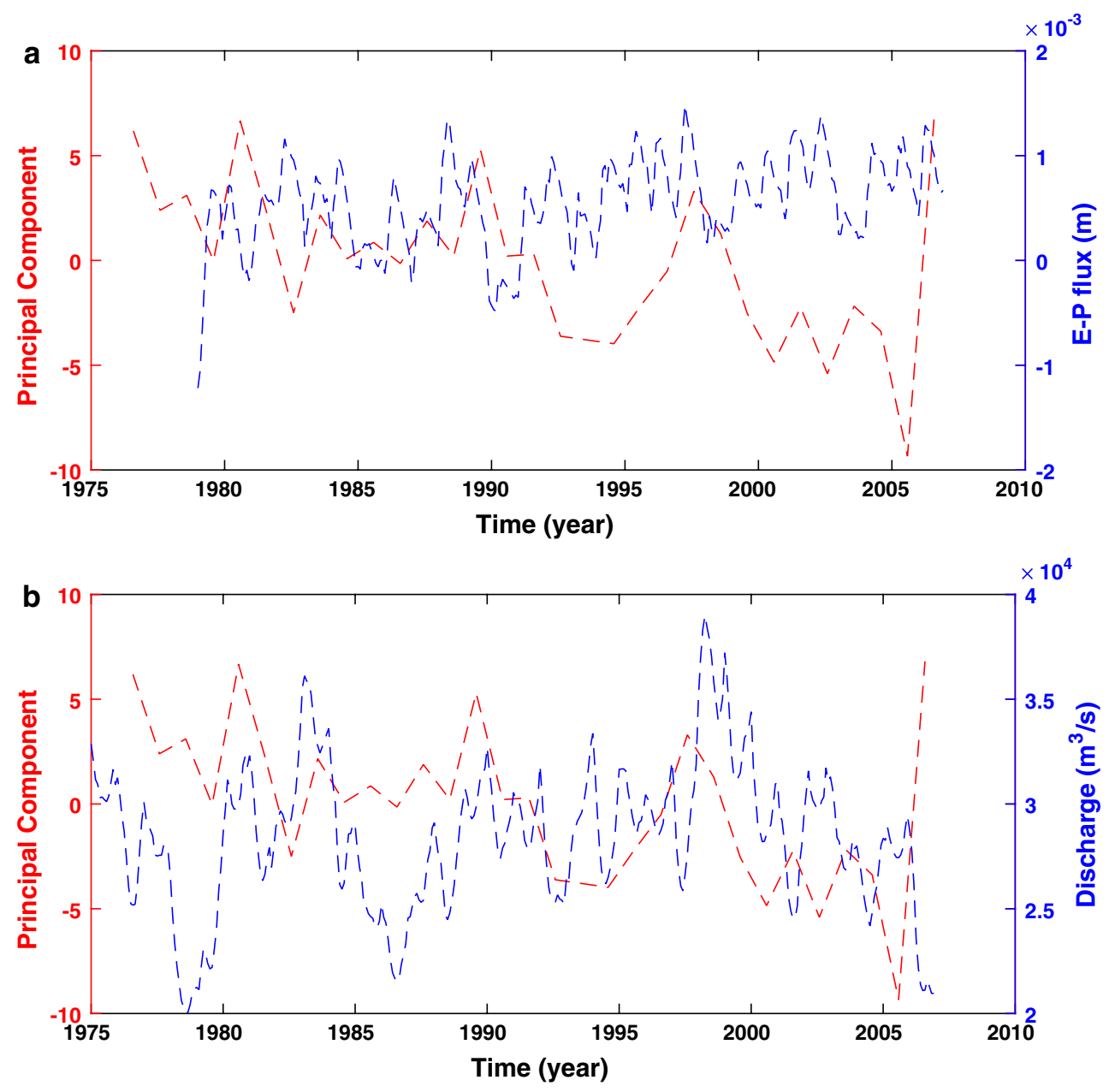

Fig. 11 a The monthly area-average of the E-P flux (blue dashed lines) and the first EOF principal component of the $36^{\circ} \mathrm{N}$ section in summer (red dashed lines); $\mathbf{b}$ the monthly Changjiang River dis- charge at the Datong station (blue dashed lines) and the first EOF principal component of the $36^{\circ} \mathrm{N}$ section in summer (red dashed lines) 
Fig. 12 The lag correlation coefficients of the E-P flux with the first EOF principal component of the $36^{\circ} \mathrm{N}$ section in summer (red dashed lines) and the monthly Changjiang River discharge at the Datong station with the first EOF principal component of the $36^{\circ} \mathrm{N}$ section in summer (blue dashed lines)

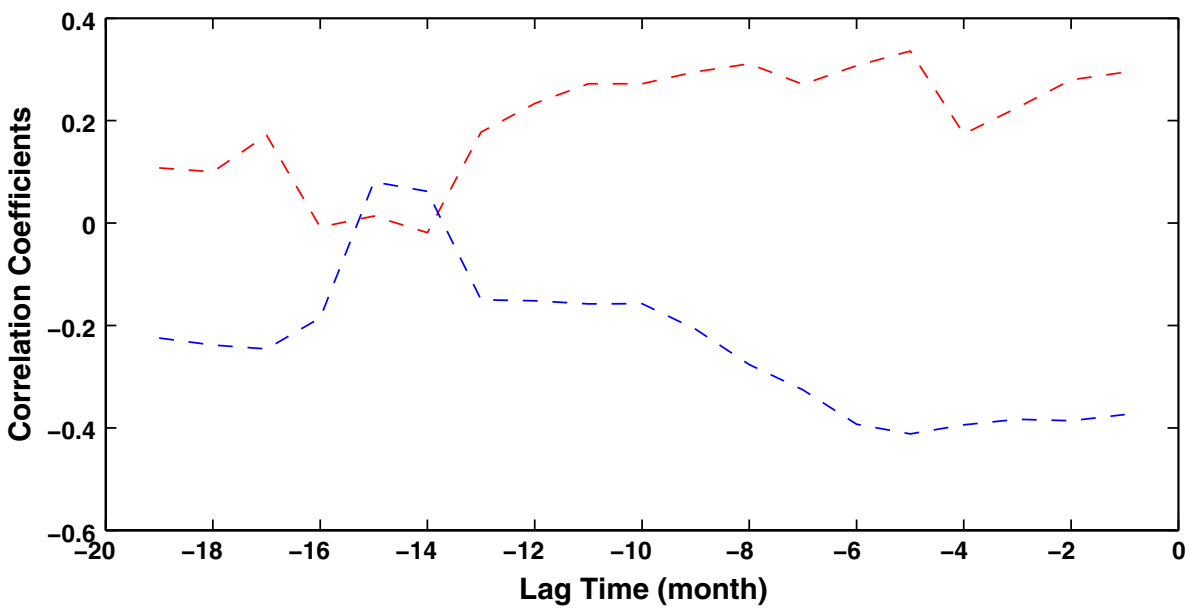

and precipitation conditions in the YS. Figures 11a and 12 (red dashed line) show that the first principal component of the SYSCWM has positive coherence with the E-P flux, with a lag of 5 months. The correlation coefficient was about 0.33 , at a significance level of $90 \%$, meaning that the evaporation and precipitation signals accumulated at the surface layer and altered the salinity of the upper layers. The surface salinity may affect the deep layers of the YS by strong vertical mixing in winter.

River discharge is also a source of freshwater. The Changjiang River is the most significant runoff input for the East China Sea. The monthly discharge of the Datong station was used to represent the freshwater input of the Changjiang River. The Changjiang River discharge demonstrated negative coherence with the first principal component of the SYSCWM in summer, with a lag of approximately 5 months (Figs. 11b, 12). The correlation coefficient for these two indices was -0.41 , with a $90 \%$ significance level.

Correlation analysis shows that freshwater input will affect the interannual variation in the salinity of the surface layer of the YS. The freshwater signal may be brought to the deep layers, which can affect the SYSCWM salinity through the YS circulation and vertical mixing in winter.

\section{Conclusions}

In this work, we identified the characteristics of a longterm variation trend in the SYSCWM and examined causes of the trend. The KODC dataset, the China standard section dataset, SODA reanalysis data, and the ERA-Interim dataset were used.

The salinity of the SYSCWM showed a decreasing trend, with both weighted mean salinity and maximum salinity decreasing. The linear trend analysis for the $36^{\circ} \mathrm{N}$ section data also indicated that the salinity of the SYSCWM area had the same long-term trends. The EOF analysis results revealed that the first mode mainly showed interannual variability in the surface salinity of the $36^{\circ} \mathrm{N}$ section, and the second showed the long-term SYSCWM salinity trend. The first two modes generally reflect the interannual variation characteristics of the $36^{\circ} \mathrm{N}$ section.

The salinity of the SYSCWM was affected by the high salinity transport of the YSWC. In winter, the $36^{\circ} \mathrm{N}$ section showed a decreasing salinity trend at the central area. The average salinity of the same area in winter showed a positive correlation with the SYSCWM salinity in summer. Lower salinity of the local water in winter led to lower salinity of the SYSCWM in summer. As the source of the SYSCWM, the freshening trend of the YSWC in winter foretells the freshening of the SYSCWM. The mean salinity of the western part of section 313 in December demonstrated positive coherence with the mean salinity of the SYSCWM area in summer and winter. The freshening trend of the YSWC source area caused reduced salinity in the SYSCWM. In addition, the Kuroshio and Taiwan Strait currents showed long-term freshening trends. The freshening water from the northwest Pacific may explain the declining salinity of the source area.

Freshwater input also played a role in the interannual salinity variability of the YS. The E-P flux and Changjiang River discharge were two important factors influencing the interannual salinity variability in the SYSCWM. The freshwater input correlated with the first principal component of the $36^{\circ} \mathrm{N}$ section, with a lag of approximately 0.5 years. The freshwater signal accumulated at the upper layer and altered the surface salinity. Strong mixing in winter and advection of the YS brought the freshwater to the SYSCWM area. 
Acknowledgements Funding was provided by National Natural Science of China (Grant No. 41306021).

Open Access This article is distributed under the terms of the Creative Commons Attribution 4.0 International License (http://creativecommons.org/licenses/by/4.0/), which permits unrestricted use, distribution, and reproduction in any medium, provided you give appropriate credit to the original author(s) and the source, provide a link to the Creative Commons license, and indicate if changes were made.

\section{References}

Bai H, Hu DX, Chen YL et al (2004) Statistic characteristics of thermal structure in the southern Yellow Sea in summer. Chin J Oceanol Limnol 22(3):237-243. doi:10.1007/BF02842554

Dee D, Uppala S, Simmons A et al (2011) The ERA-Interim reanalysis: configuration and performance of the data assimilation system. Q J R Meteorol Soc 137(656):553-597

Du B, Zhang YJ, Shan YC et al (1996) The characteristics of Cold Water Mass variation at the bottom of the north Yellow Sea and its hydrological effects on the mortality of shellfish cultured in the waters of outer Chang-Shan Island. Mar Sci Bull 15(4):17-28

Eko S, Hideaki N, Yuji M et al (2008) The long-term freshening and nutrient increases in summer surface water in the northern East China Sea in relation to Changjiang discharge variation. J Geophys Res Oceans (1978-2012) 113:C10

Guan BX (1963) A preliminary study of the temperature variations and the characteristics of the circulation of the Cold Water Mass of the Yellow Sea. Oceanol Limnol Sin 5(4):255-284

He CB, Wang YX, Lei ZY et al (1959) A preliminary study of the formation of Yellow Sea cold mass and its properties. Oceanol Limnol Sin 2(1):11-15

Hu DX, Wang QY (2004) Interannual variability of the southern Yellow Sea cold water mass. Chin J Oceanol Limnol 22(3):231236. doi: $10.1007 / \mathrm{BF} 02842553$

Hur H, Jacobs G, Teague W (1999) Monthly variations of water masses in the Yellow and East China Seas. J Oceanogr 55(2):171-184. doi:10.1023/A:1007885828278

Jiang BJ, Bao XW, Wu DX et al (2007) Interannual variation of temperature and salinity of northern Huanghai Sea Cold Water Mass and its probable cause. Acta Oceanol Sin 29(4):1-10. doi:10.3321/j.issn:0253-4193.2007.04.001

Lee SH, Beardsley RC (1999) Influence of stratification on residual tidal currents in the Yellow Sea. J Geophys Res Oceans 104(C7):15679-15701. doi:10.1029/1999JC900108

Li A, Yu F, Diao XY et al (2015) Interannual variability of temperature of northern Yellow Sea Cold Water Mass. Acta Oceanological Sinica 37(1):30-42. doi:10.3969/j.issn.0235-4193.2015.01.004

Lie HJ, Cho CH, Lee JH et al (2000) Seasonal variation of the Cheju warm current in the northern East China Sea. J Oceanogr 56(2):197-211

Lin C, Su J, Xu B, Tang Q (2001) Long-term variations of temperature and salinity of the Bohai Sea and their influence on its ecosystem. Prog Oceanogr 49(1):7-19. doi:10.1016/ S0079-6611(01)00013-1

Lin CL, Ning XR, Su JL et al (2005) Environmental changes and the responses of the ecosystems of the Yellow Sea during 1976-2000. J Mar Syst 55(3):223-234. doi:10.1016/j.jmarsys.2004.08.001
Lv C-L, Bao X-W, Wu D-X et al (2009) Analysis of decadal variability and interannual variability of salinity field in Bohai and Northern Yellow Sea in winter. Period Ocean Univ China 39(suppl):267-273

Ma J, Qiao FL, Xia CS et al (2006) Effects of the Yellow Sea Warm Current on the winter temperature distribution in a numerical mode. J Geophys Res Oceans 111:C11

Nan F, Yu F, Xue H et al (2015) Ocean salinity changes in the northwest Pacific subtropical gyre: the quasi-decadal oscillation and the freshening trend. J Geophys Res Oceans 120(3):2179-2192

Park S, Chu PC, Lee JH (2011) Interannual-to-interdecadal variability of the Yellow Sea Cold Water Mass in 1967-2008: characteristics and seasonal forcings. J Mar Syst 87(3):177-193. doi:10.1016/j. jmarsys.2011.03.012

Park KA, Lee EY, Chang E et al (2015) Spatial and temporal variability of sea surface temperature and warming trends in the Yellow Sea. J Mar Syst 143:24-38

Ren HJ, Zhan JM (2005) A numerical study on the seasonal variability of the Yellow Sea cold water mass and the related dynamics. J Hydrodyn 20(suppl):887-896. doi:10.3969/j.issn.10004874.2005.z1.012

Su YS, Weng XC (1994) Water masses in China seas. In: Zhou D et al (eds) Oceanology of China Seas. Kluwer Academic Publishers, The Netherlands, pp 3-16

Uda M (1934) Hydrographical reasearches on the normal monthly conditions in the Japan Sea, the Yellow Sea, and the Okhotsk Sea. J Imp Fish Exp Sta 5:191-236

Wang R, Zuo T, Wang K (2003) The Yellow Sea cold bottom wateran oversummering site for Calanus sinicus (Copepoda, Crustacea). J Plankton Res 25(2):169-183. doi:10.1093/plankt/25.2.169

Wang H, Yu F, Lv L (2009) Characteristics of spatial and interannual variation in the Yellow Sea Warm Current area in winter. Adv Mar Sci 27(2):140-148. doi:10.3969/j.issn.1671-6647.2009.02.003

Wei H, Shi J, Lu Y et al (2010) Interannual and long-term hydrographic changes in the Yellow Sea during 1977-1998. Deep Sea Res Part II 57(11):1025-1034. doi:10.1016/j.dsr2.2010.02.004

Weng XC, Zhang YK, Wang CM et al (1988) The variational characteristics of the Huanghai Sea (Yellow Sea) Cold Water Mass. Oceanol Limnol Sin 19(1):368-379

Wu D, Mou L, Li Q, Bao X, Wan X (2004) Long-term variation of salinity of Bohai Sea and its probable primary cause. Prog Nat Sci 14(02):191-195. doi:10.3321/j.issn:1002-008X.2004.02.012 (in Chinese with English abstract)

Yang HW, Cho YK, Seo GH et al (2014) Interannual variation of the southern limit in the Yellow Sea Bottom Cold Water and its causes. J Mar Syst 139:119-127. doi:10.1016/j. jmarsys.2014.05.007

Yu F, Zhang ZX, Diao XY et al (2006) Analysis of evolution of the Huanghai Sea Cold Water Mass and its relationship with adjacent water masses. Acta Oceanol Sin 28(5):26-34. doi:10.3321/j. issn:0253-4193.2006.05.003

Zhang YK, Yang YL (1996) Analyses of the variational characteristics of the north Huanghai Sea Cold Water Mass. Mar Forecasts 13(4):15-21

Zhang G, Sun S, Yang B (2007) Summer reproduction of the planktonic copepod Calanus sinicus in the Yellow Sea: influences of high surface temperature and cold bottom water. J Plankton Res 29(2):179-186. doi:10.1093/plankt/fbm005

Zhao BR (1986) The fronts of the Huanghai cold water mass (HCWM) induced by tidal mixing. Chin J Oceanol Limnol 4(2):159-170. doi:10.1007/BF02850432 